\title{
Ocular Health Status of Diabetes Mellitus Patients in Uyo, South- South Nigeria
}

\author{
Abraham, Emem Godwin ${ }^{1,}$ Umoh, Victor ${ }^{2}$ \\ Department of ophthalmology, University of Uyo Teaching Hospital, Uyo, Nigeria \\ Department of internal Medicine, University of Uyo Teaching Hospital, Uyo, Nigeria
}

\begin{abstract}
Background: Diabetes mellitus is one of the systemic diseases with serious ocular complications. Ocular complications from diabetes mellitus could result from the microangiopathy and changes in the lens largely from poor gylcaemic control. Ocular complications also depend on duration of diabetes and presence or absence of other co-morbid conditions like hypertension. Since majority of the complications occur without prior symptoms, there is need for improved level of awareness in the community. This can only occur from a background of knowledge, hence this study.

Materials and method: Interviewer administered questionnaire was administered to 218 consenting diabetic patients who were previously diagnosed or diagnosed in the eye clinic between January 2009 and December 2010. Ocular examination was carried out by the investigator. Result so obtained was analysed using SPSS17.0 statistical package. Result obtained presented as simple tables

Results: Of the 218 diabetic patients examined, cataract was the commonest anterior segment finding $(56.4 \%)$, while non proliferative diabetic retinopathy was commonest posterior segment finding (31\%).glaucomatous disc cupping was seen in (11.4\%).

Conclusion: Diabetic eye complications are a public health problem hence the need for improved level of awareness and development of diabetic screening programmes in our community.
\end{abstract}

Key words: cataract, diabetes mellitus, retinopathy, rubeosis

\section{Introduction}

Diabetes mellitus (DM) refers to a group of metabolic disorders that share the phenotype of hyperglycemia [1]. DM is caused by a complex interaction of genetic and environmental factors [2]. Factors that contribute to hyperglycemia include reduced insulin secretion [3, 4], decreased glucose utilization $[5,6]$ and increased glucose production [7]. The metabolic dysregulation associated with DM causes secondary pathophysiologic changes in multiple organ systems that impose a tremendous burden on the patient and on the health care system [8]. Worldwide DM is the leading cause of end-stage renal disease (ESRD), non-traumatic lower extremity amputations, and adult blindness in the industrialised world [9]Considerable data indicate that diabetes is one of the leading causes of blindness in industrialized countries. It accounts for $10 \%$ of all new cases of blindness and $20 \%$ of new cases of blindness diagnosed between the ages of 45 and 74 years [10]. Data indicate that blacks may suffer a disproportionate burden of blindness from diabetes [11].

Diabetic retinopathy is a well-known ocular complication of diabetes and the leading cause of blindness among people 20-64 years of age in the U.S [12]. Up to 4 million Americans with diabetes, 40 years of age and older, have retinopathy, and nearly one million have sight-threatening retinopathy [13] . In major clinical trials, tight control of blood glucose and blood pressure has been demonstrated to reduce the risk of retinopathy and associated blindness [14].

Other ocular conditions that are directly associated with DM include; cataracts [15], anterior ischemic optic neuropathy [16], diabetic papillopathy [17] and ocular movement disorders [18, 19]. Some other conditions have DM as a known risk factor. These are; primary open angle glaucoma [20] and secondary neovascular glaucoma [21] as well as ocular ischemic syndrome [22]. DM is a possible risk factor for these other ocular conditions; retinal vein occlusion [23], retinal arteriolar emboli [24], retinal artery occlusion [25] and corneal diseases such as corneal erosion, persistent epithelial defect, or corneal ulcers [26].

Most of these conditions are directly related to poor glycaemic control while [10] some are epidemiologically associated with DM [27].

Ocular complications when they appear, reduce the quality of life of DM patients and are also associated with increased morbidity and mortality [28]. Good long term glycaemic control is associated with a reduction in the prevalence of these ocular complications [10].

Studies have shown that glycaemic control among DM patients is poor worldwide [29] local studies have demonstrated a similar trend [30,31] and this predisposes patients to eye diseases. This study was carried out to determine the ocular health status of DM patients who presented in the eye clinic of a tertiary hospital. 


\section{Materials and methods}

This was a prospective study carried out in Uyo metropolis, the capital of Akwa Ibom State, in SouthSouth Nigeria. It is essentially urban with an estimated population of 554,006 people according to 2006 national population census [32]. All consecutive new patients presenting in the eye clinic between January 2009 and December 2010 with previously diagnosed DM and those whose assessed fasting blood sugar (FBS) levels when tested in the eye clinic was $>/ 7.00 \mathrm{mml} / \mathrm{L}$ and who consented were included in the study. Interviewer administered structured questionnaire were administered to the patient after proper explanation and consent had been obtained. These questionnaires assessed the bio data of the patients, duration of DM, family history, treatment methods and level of control of DM, co-morbid conditions such as hypertension (HTN), and eye examination findings.

Visual acuity was carried by the ophthalmic nurses and all other ocular examination were carried out by the ophthalmologist which included parameters like; anterior segment examination, direct fuduscopy and intraocular pressure(IOP).

Distant visual acuity was assessed using the Snellen's chart and near vision with near vision chart. Anterior segment examination was done using penlight with $\mathrm{x} 7$ head loupe and a slit lamp. Posterior segment examination was carried out with Heine direct ophthalmoscope. Pupils were dilated with $1 \%$ tropicamide for dilated funduscopy. Intraocular pressure (IOP) was measured using Perkin's hand held tonometer. Clinical measurements like weight, height were taken and BMI calculated

Patients diagnosed with DM before the age of 30years were classified as type 1 DM while those diagnosed after 30 years were diagnosed as type 11. Patients with no previous history of DM but with blood sugar of $\geq 7.0 \mathrm{mmol} / \mathrm{L}$ during pregnancy were diagnosed as gestational DM

Results obtained were analysed using SPSS17.0 and presented as simple tables and frequencies. A $P$-value of 0.5 was considered significant.

\section{Result}

A total of 218 patients made up of 102 males (46.8\%) and 116 females (53.2\%) giving a male to female ratio of 1:1.14. The age range of the patients was between 19years and 82years and mean age of $54.72 \pm 17.68$ years. Majority had type 2 DM (94.5\%) while $10(4.6 \%)$ had type1 DM and 2(0.9\%) had gestational DM. Duration of DM was between 2 weeks and 20years. Majority had duration of DM of $\leq 5$ years. There was family history of DM in first degree relative in 131(60.1\%).

Blurring of vision was the commonest eye complaint (194) with (76) of the patients having blurring of vision as the only complaints. One hundred and thirty nine (64.4\%) had visual acuity (VA) 6/18 or better in the right eye (RE) $62.0 \%$ in the left eye. Cataract was the commonest anterior segment complication (123), while non-proliferative retinopathy was the commonest posterior segment complication (120). Systemic complication was reported in 17 (7.8\%). Coexisting glaucomatous disc cupping was seen in 25 patients. Other coexisting posterior segment complications include posterior vitreous detachment (one), retinal detachment (two), retinitis pigmentosa(two). One hundred and thirty seven (62.8\%) had coexisting HTN.

Table1: Age and Sex distribution of 218 DM patients in Uyo

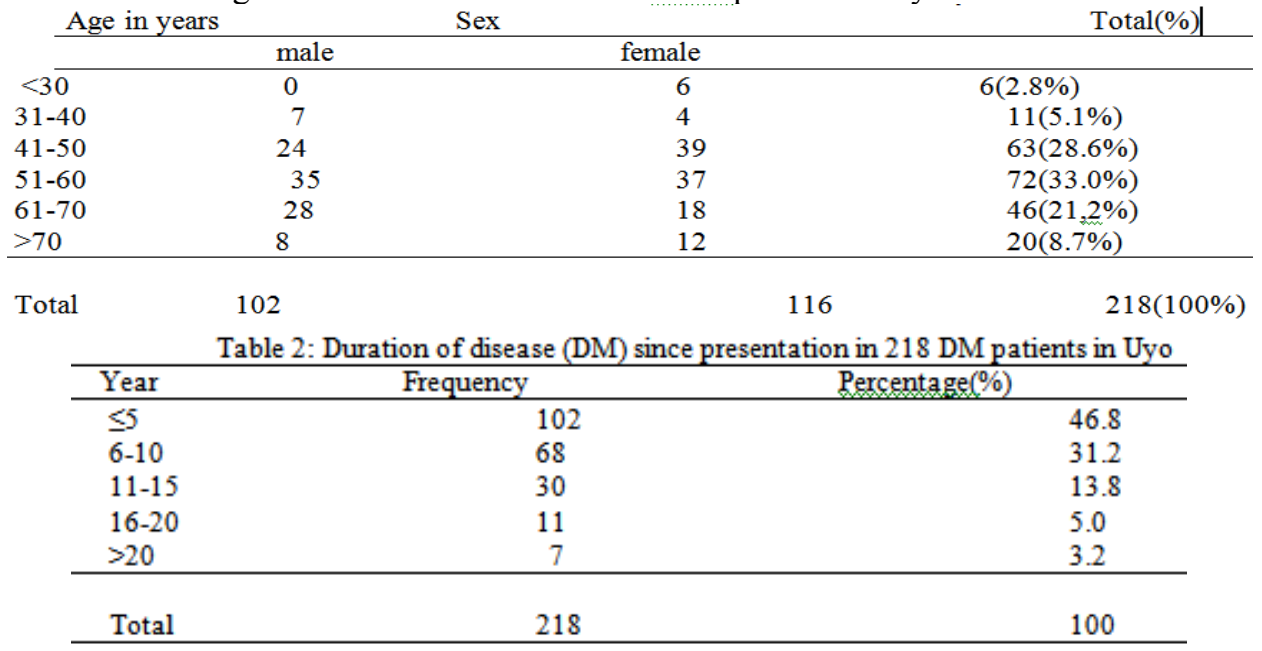




\begin{tabular}{lrr}
\hline & RE & LE \\
& Frequency (\%) & frequency $(\%)$ \\
\hline $6 / 6$ & $30(13.9 \%)$ & $24(11.1 \%)$ \\
$6 / 9$ & $43(19.9 \%)$ & $46(21.3 \%)$ \\
$6 / 12$ & $33(15.3 \%)$ & $29(13.4 \%)$ \\
$6 / 18$ & $33(15.3 \%)$ & $35(16.2 \%)$ \\
$6 / 24$ & $22(10.2 \%)$ & $22(10.2 \%)$ \\
$6 / 36$ & $25(11.5 \%)$ & $22(10.8 \%)$ \\
$6 / 60$ & $11(5.0 \%)$ & $15(6.9 \%)$ \\
$\mathrm{CF}^{*}$ & $15(6.9 \%)$ & $13(6.0 \%)$ \\
$\mathrm{HM} / \mathrm{PL}^{\#}$ & $4(1.8 \%)$ & $7(6.0 \%)$ \\
$\mathrm{NPL}$ & $2(0.9 \%)$ & $2(0.5 \%)$ \\
\hline Total & & \\
\hline
\end{tabular}

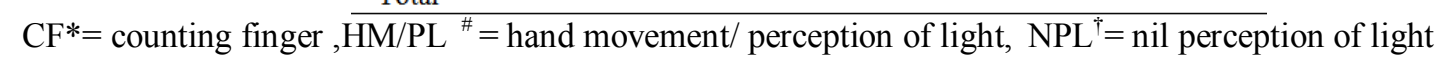

Table4: Distribution of eye findings in the eyes of 218 DM patients in Uyo

\begin{tabular}{|c|c|c|c|c|}
\hline Eye findings & Frequency & & percent age $(\%)$ & \\
\hline Lagophthalmos & 2 & & 0.9 & \\
\hline Rubeosis/hyphyaema & & 1 & & 0.5 \\
\hline Cataract & 123 & & $56.4 \%$ & \\
\hline Pseudophakia & & 3 & & 1.3 \\
\hline Disc cupping & 27 & & 12.4 & \\
\hline Disc neovascularisation & 2 & & 0.9 & \\
\hline Macula oedema & 44 & & 20.2 & \\
\hline Retinal Vascular abnormalities & 53 & & 24.3 & \\
\hline Haemorrhages & 18 & & 8.3 & \\
\hline Cotton wool exudates & & 22 & & 10.6 \\
\hline Hard exudates & & 30 & & 13.6 \\
\hline Haemorrhages +exudates & 42 & & 19.3 & \\
\hline RD*PVD\# & & 3 & & 1.3 \\
\hline Pigment clumps & 2 & & 0.9 & \\
\hline
\end{tabular}

$\mathrm{RD}^{*}=$ retinal detachment, $\mathrm{PVD} \#=$ posterior vitreous detachment

\section{Discussion}

Diabetic retinopathy remains the most well-known ocular complications of DM and the commonest cause of blindness among people20-64years in the United States of America (USA) [12]. There are also other sight threatening ocular complications of DM which are none the less important as far as diabetic eye health is concerned. DM was once believed to be the disease of the industrialised nations but now seen as an epidemic affecting the whole world[33].

In this series, 218 patients were studied, 102 males and 116 females with M:F ratio of1: 1.14. There was a female preponderance as seen in other studies[34,35]. The study population was between the ages of 19 years and 82years, with a mean age of $54.72 \pm 17.68$ years. Diabetes was highest in the 51-60 age group, similar to the finding by Lawan in Kano- northern Nigeria (35), Shrestha in Nepal (36). This may be so probably because this age group are likely to experience symptoms of other age related eye diseases and so occurrence of diabetic eye complications will further worsen their eye health status causing them to seek medical attention early. Only 6(2.8\%) were less than 30years old.

One hundred and thirty nine (64.4\%) had visual acuity (VA) 6/18 or better in the right eye(RE) $62.0 \%$ in the left eye. This is lower than the findings in Nepal (85.93\%)(36). The visual acuity in this study was the presenting VA while that of Nepal was best corrected VA. Two $(0.9 \%)$ were blind in the RE at presentation while19 ( 8.7\%) had uncorrected VA of $<3 / 60$ in the RE Two $(0.9 \%)$ had lagophthalmos as neurophthalmic complication of DM. Incidence of cranial nerve palsies in DM patients was seen to be significantly higher than in non DM patients according to a study by Watanabe $\mathrm{K}$. in Tokyo[37] but facial nerve palsy was less strongly correlated with DM as compared to ophthalmoplagia. Rubeosis iridis and hyphaema was seen in 1 patient each $(0.5 \%)$.Neovascularisation of the iris is often followed by neovascular glaucoma, with its associated risk of blindness and pain[38]. Rubeosis often points to microangiopathy, necessitating the evaluation of the patients for other microangiopathies, such as retinopathy[39]. The prevalence of cataract in our series was $56.4 \%$. This is higher than that observed in Bengazi,(Libya) (13.1\%)[40] but close to what is seen in a study in West Africa(44.9\%)[41] and (54.68\%) in Nepal[36]. Cataract is a major cause of visual impairment in people with diabetes[12,42]). The diagnosis of cataract was based on morphologic changes observed on slit lamp examination. A variety of publications support the hypothesis that the initiating mechanism in diabetic cataract formation is the generation of polyols from glucose by aldose reductase enzyme (AR), which results in increased osmotic stress in the lens fibres leading to their swelling and rupture and eventual cataract 
formation[43]. The Blue Mountain Eye Study showed that impaired fasting glucose in the absence of clinical DM was also a risk factor for the development of cortical cataract[44]. Glaucomatous disc cupping was seen in $25(11.4 \%)$. This is higher than that observed in Sana Yemen(8.6\%)[45]. Prevalence of glaucoma is higher in black population than Caucasians[46]. Diabetics are at risk of both primary open angle glaucoma and neovascular glaucoma. Glaucoma occurs more often in patients with diabetes $(5 \%)$ than the general population(2\%)(47). The risk of glaucoma has been reported to be 1.6-4.7 times higher in individuals with diabetes than in non diabetic individuals $(48,49]$. Non proliferative Diabetic retinopathy (NPDR) was seen in $120(31.1 \%)$. This is similar to the findings in Benghazi(30.6\%)(37] using the same method of examination. It is lower than many other studies where more sensitive methods of examination were used: Nnewi, Nigeria (33\%),[50] Kano, Nigeria(36\%),[35] Yemen(54.9\%)[45] in Jordan(64.1\%)J . The mean age of this study population was 54years. Older patients especially those with prolonged disease are more likely to develop diabetic retinopathy. Other funduscopic findings were retinal detachment (RD)/posterior vitreous detachment (PVD ) 5 eyes, retinitis pigmentosa(RP) 2eyes. Majority of the patients were treated with oral hypoglycaemic agents162 (74.3\%). Of this, control was only achieved in 77(47.5\%) as compared to39.1\% achieved by using insulin. This was not statistically significant $P=0.73$, but consistent with findings from other authors that control of DM is generally poor amongst patients (29).

The limitations of this study included the fact that it was a hospital based study with institutional bias and the lack of more sensitive equipment for examination

\section{Conclusion}

Diabetes is an important risk factor for several causes of visual impairment and blindness. A significant number of the patients in our study were first diagnosed with diabetes in the eye clinic when they presented with ocular complications. The management of diabetes related eye diseases is primarily preventive. It is therefore important that current level of eye health education be improved upon such that both those diagnosed with DM and those with family history of DM will appreciate the need for regular eye examination because regular eye examination and appropriate ophthalmological referral remains the key strategy to reducing the impact of diabetes -related vision loss.

\section{References}

[1]. Expert Committee on the Diagnosis and Classification of Diabetes Mellitus Report of the Expert Committee on the Diagnosis and Classification of Diabetes Mellitus. Diabetes Care, 1997;20: 1183 -1197.

[2]. Stumvoll M, Goldstein BJ, van Haeften TW. Type 2 diabetes: principles of pathogenesis and therapy. Lancet 2005; 365:1333-1346.

[3]. Weyer C, Bogardus C, Mott DM, Pratley RE. The natural history of insulin secretory dysfunction and insulin resistance in the pathogenesis of type 2 diabetes mellitus. J Clin Invest 1999; 104:787-794

[4]. Haffner SM, Miettinen H, Gaskill SP, Stern MP. Decreased insulin secretion and increased insulin resistance are independently related to the 7-year risk of NIDDM in Mexican-Americans. Diabetes 1995; 44:1386-1391.

[5]. Rothman DL, Magnusson I, Cline G, Gerard D, Kahn CR, Shulman RG et al. Decreased muscle glucose transport/phosphorylation is an early defect in the pathogenesis of non-insulin-dependent diabetes mellitus. Proc Natl Acad Sci U S A 1995; 92:983-987

[6]. Petersen KF, Dufour S, Befroy D, Garcia R, Shulman GI. Impaired mitochondrial activity in the insulin-resistant offspring of patients with type 2 diabetes. N Engl J Med 2004; 350:664-671

[7]. Harris MI, Flegal KM, Cowie CC, Eberhardt MS, Goldstein DE, Little RR et al. Prevalence of diabetes, impaired fasting glucose, and impaired glucose tolerance in U.S. adults. The Third National Health and Nutrition Examination Survey, 1988-1994. Diabetes Care 1998; 21:518-524.

[8]. World Health Organization/International Diabetes Federation. The Economics of Diabetes and Diabetes Care: A Report of the Diabetes Health Economics Study Group. Geneva: WHO/IDF. 1999

[9]. American Diabetes Association. Diagnosis and classification of diabetes mellitus. Diabetes Care. 2007;30(S1 1):S42-7.

[10]. Akinkugbe OO. Final report of national survey on non communicable diseases in Nigeria series 1. Federal Ministry of Health and social Service, Lagos;1997

[11]. UK Prospective Diabetes Study (UKPDS) Group. Intensive blood-glucose control with sulphonylureas or insulin compared with conventional treatment and risk of complications in patients with type 2 diabetes (UKPDS 33). Lancet 1998; 352: 837-53.

[12]. Kahn HA, Hiller R. Blindness caused by diabetic retinopathy. Am J Ophthalmol. 1974; 78: 58-67.

[13]. Congdon NG, Friedman DS, Lietman T. Important causes of visual impairment in the world today. JAMA 2003; 290:2057-2060.

[14]. Kempen JH, O' Colmain BJ, Leske MC, Haffner SM, Klein R, Moss SE et al. The prevalence of diabetic retinopathy among adults in the United States. Arch Ophthalmol 2004; 122:552-563.

[15]. Mohamed Q, Gillies MC, Wong TY. Management of diabetic retinopathy: a systematic review. JAMA 2007; 298:902-916.

[16]. Saxena S, Mitchell P, Rochtchina E. Five year incidence of cataract in older persons with diabetes and pre-diabetes. Ophthalmic Epidemiol 2004; 11:271-277.

[17]. Ischemic Optic Neuropathy Decompression Trial Study Group. Characteristics of patients with non-arteritic anterior ischemic optic neuropathy eligible for the Ischemic Optic Neuropathy Decompression Trial. Arch Ophthalmol 1996; 114: 1366-1374.

[18]. Bandello F, Menchini F. Diabetic papillopathy as a risk factor for progression of diabetic retinopathy. Retina 2004; 24:183-184.

[19]. Rush JA. Extraocular muscle palsies in diabetes mellitus. Int Ophthalmol Clin 1984;24: 155-9.

[20]. Watanabe K, Hagura R, Akanuma Y, Takasu T, Kajinuma H, Kuzuya N et al. Characteristics of cranial nerve palsies in diabetic patients. Diabetes Res Clin Pract 1990 10:19-27.

[21]. Hennis A, Wu S, Nemesure B, Leske MC. Hypertension, diabetes, and longitudinal changes in intraocular pressure. Ophthalmology 110:908-914, 2003

[22]. Schertzer RM, Wang D, Bartholomew LR: Diabetes mellitus and glaucoma. Int Ophthalmol Clin 1998; 38:69-87

[23]. Mizener JB, Podhajsky P, Hayreh SS. Ocular ischemic syndrome. Ophthalmology 1997; 104:859-864. 
[24]. Shahsuvaryan ML, Melkonyan AK. Central retinal vein occlusion risk profile: a case-control study. Eur J Ophthalmol 2003; 13: 445-452.

[25]. Dielemans I, de Jong PT, Stolk R.,Vingerling JR, Grobbee DE, Hofman A. Primary open-angle glaucoma, intraocular pressure, and diabetes mellitus in the general elderly population: the Rotterdam Study. Ophthalmology 1996; 103:1271-1275.

[26]. Recchia FM, Brown GC. Systemic disorders associated with retinal vascular occlusion. Curr Opin Ophthalmol 2000; 11: 462-467.

[27]. Didenko TN, Smoliakova GP, Sorokin EL, Egorov VV. Clinical and pathogenetic features of neurotrophic corneal disorders in diabetes. Vestn Oftalmol 1999; 115:7-11,

[28]. Swetha V, Jeganathan E, Wang J, Wong TN . Ocular associations of diabetes other than diabetic retinopathy. Diabetes Care 2008; 31(9) 1905- 1912

[29]. Cusick M, Meleth AD, Agrón E, Fisher MR, Reed GF, Knatterud GL et al and Early Treatment Diabetic Retinopathy Study (ETDRS) Research Group. Associations of Mortality and Diabetes Complications in Patients With Type 1 and Type 2 Diabetes: Early Treatment Diabetic Retinopathy Study report no. 27. Diabetes Care 2005; 28:617-625

[30]. Eeg-Olofsson K, Cederholm J, Nilsson PM, Gudbjörnsdóttir S, Eliasson B. for the Steering Committee of the Swedish National Diabetes Register. Glycemic and Risk Factor Control in Type 1 Diabetes Results from 13,612 patients in a national diabetes register. Diabetes Care 2007; 30(3): 496-502

[31]. Adebisi SA, Oghagbon EK, Akande TM, Olarinoye JK. Glycated haemoglobin and glycaemic control of diabetics in Ilorin. Niger J Clin Pract 2009; 12:87-9

[32]. Nigeria demographic and health surveys. National population commissionl2008. http/www. Population.gov.ng cited 12/04/2010

[33]. King H,Rewers M.Diabetes in adults is now a third world problem. The WHO Ad Hoc Diabetes reporting group: Bull World Health Organ;1991:69(6):643-648

[34]. Mohammed I,WaziriAM. Awareness of diabetic retinopathy amongst diabetic patients at Mortal Mohammed hospital, Kano, Nigeria. Niger Med J2009;50:38-41

[35]. Lawan A, Mohammed TB. Pattern of diabetic retinopathy in Kano,Nigeria. Anna ls of African Medicine 2012;11(2) 75-79

[36]. Shrestha RK. Ocular manifestations in diabetes, a hospital based prospective study. Nepal Med Coll J 2011:13(4):254-256

[37]. Watanabe K, Hagura R,Akenuma Y et al: Characteristics of cranial nerve palsies in diabetic patients. Diabetes Res Clin Pract. 1990 Aug-Sep;10 (1) 19-27

[38]. Madsen RH: Rubeosis of the iris and haemorrhagic glaucoma in patients with proliferative diabetic retinopathy. Br J Ophthalmol $1971 ; 55: 368-371$

[39]. Paron, N.G. and Lambert, P.W. (2000) Cutaneous manifestations of diabetes mellitus. Prim. Care 27, 71-83.CC

[40]. ,RB, Kadiki OA. Prevalence of longterm complications among type 2 diabetic patients in Benghazi Roaeid. Journal of Diabetology, 2011; $3: 5$ (October 2011)

[41]. Rotimi C, DanielH, ZhonJ, ObisekenA,,Chen G, ChenI, AnwahA et al. Prevalence and determinants of diabetic retinanopathy with cataract in West African type2 diabetes patient. 2003, 13 (2)1107 \{Pubmed

[42]. Klein BE, et al: Older-onset diabetes and lens opacities: the Beaver Dam Eye Study. Ophthalmic Epidemiol 2:49-55,2005 \{Pubmed

[43]. Pollreisz A,Schmidt-Erfurth U: Diabetic cataract-pathogenisis, epidemiology and treatment. J Ophthalmol 2010 oil155/2012/608751 \{PMCfree article][Pubmed]

[44]. Rowe NG, Mitchell PG,Cumming RG, Wans JJ: Diabetes blood glucose and age-related cataract: Blue Mountains Eye Study. Ophthalmic Epidemiol 2000 Jun;7(2):103-114. [Pubmed]

[45]. Bamash MA,Gunaid AA, Khandekar RB. Diabetic retinopathy, visual impairment and ocular status among patients with diabetes mellitus in Yemen: A hospital-based study. Indian J ophthalmol 2009;57:293-298

[46]. James Met al. Racial variations inthe prevalence of primary open angle glaucoma. The Baltimore Eye Study. JAMA1991; 266(3) 369-374

[47]. Bernth-Petersen P,Bach E: Epidimiological aspects of cataract.111. Frequencies of diabetes and glaucoma in a cataract population. Acta Ophthalmol(Copenh) 1983; 61:406-416.

[48]. Katz J, Sommer A:Risk factors for primary open angle glaucoma. Am J Prev Med 1988; 4:110-114

[49]. Reynolds DC: Relative risk factors in chronic open-angle glaucoma: an epidemiological study. Am J Optom Physiol Opt 54: 116$120,1977$.

[50]. Nwosu SNN: Diabetic retinopathy in Nnewi, Nigeria J Ophthalmol; 2000:8(1) :7-10 